\title{
ПРАВОВОЕ РЕГУЛИРОВАНИЕ ЭКОЛОГИЧЕСКОГО ПРЕДПРИНИМАТЕЛЬСТВА В СОЕДИНЕННЫХ ШТАТАХ АМЕРИКИ
}

\section{LEGAL REGULATION OF ENVIRONMENTAL ENTREPRENEURSHIP IN THE UNITED STATES OF AMERICA}

\section{A. Ellarian}

Summary. Subject / topic. Subject of the scientific research is theoretical and legal basis for regulation of enviromental entrepreneurship in the United States of America.

Goals / objectives. The goal and objectives of the research is to study the theoretic and legal basis of environmental entrepreneurship in doctrine the United States of America.

Methodology. The article uses general scientific research methods: empirical cognition methods (description, interpretation), theoretical research methods (formal and dialectical logic, systematic method), as well as analysis, synthesis, induction and deduction.

Conclusion. Environmental entrepreneurship is an effective solution to environmental problems that often arise, which requires legislative regulation of this field. The author of the article considered experience of environmental enterprises regulation in the United States of America, doctrinal definitions of environmental entrepreneurship, identified a tendency towards environmentalization of law; environmental entrepreneurship is regarded as a part of environmental law (ecological law) in the USA; there is a high level of self-regulation of relations in the field of environmental entrepreneurship, in particular creation of industry standards, recommendation to incorporate and incorporation of benefit corporations that allow for environmental entrepreneurship without exposing managers and directors to the risk of being held liable by shareholders if acting in accordance with charter of the corporation. The author considered possibility of applying experience of the United States of America in the field of environmental entrepreneurship regulation in the Russian Federation and made a conclusion on possibility of regulation in the field of ecological markings in the Russian Federation based on Green Guides adopted by the Federal Trade Commission of the USA; the author offered to apply requirements for benefit corporations as basis for requirements for environmental entrepreneurship in the Russian Federation.

Keywords: entrepreneurship, environmental entrepreneurship, definition, environmental entrepreneurship in the United States, Benefit corporation, Green Guides.

\author{
Элларян Артур Сашикович \\ Аспирант, Финансовый университет при \\ Правительстве Российской Федерации \\ tlon9@rambler.ru
}

Аннотация. Предмет/тема. Предметом научного исследования являются теоретико-правовые основы регулирования экологического предпринимательства в Соединенных Штатах Америки.

Цели/задачи. Целью и задачами исследования являются изучение теоретико-правовых основ экологического предпринимательства в доктрине Соединенных Штатов Америки, изучение текущего состояния в сфере правового регулирования экологического предпринимательства в Соединенных Штатах Америки.

Методология. В статье использованы общенаучные методы исследования: методы эмпирического познания (описание, интерпретация), теоретические методы исследования (формальной и диалектической логики, системный метод), а также анализ, синтез, метод индукции и дедукции.

Вывод. Эффективным инструментом решения все чаще возникающих экологических проблем является экологическое предпринимательство, что порождает необходимость правового регулирования в указанной сфере. Автором статьи рассмотрен опыт регулирования экологического предпринимательства в Соединенных Штатах Америки, доктринальные дефиниции экологического предпринимательства, выявлена тенденция к экологизации права, само же экологическое предпринимательство в США рассматривается в рамках права окружающей среды (экологического права), также проявляется высокий уровень саморегулирования отношений в сфере экологического предпринимательства, в частности установление отраслевых стандартов, рекомендация к применению и применение такой корпоративной формы как корпорация осуществляющая деятельность в интересах общества, которая позволяет заниматься экологической предпринимательской деятельностью, без угрозы для директоров и менеджмента привлечения к ответственности со стороны акционеров в случае деятельности согласно уставу корпорации. Автором рассмотрена возможность применения опыта Соединенных Штатов Америки в сфере регулирования экологического предпринимательства в Российской Федерации, сформулирован вывод о возможности регулирования отношений в сфере экологических маркировок в Российской Федерации на основе «Зеленых руководств» принятых Федеральной торговой комиссией США, предложено применение требований к корпорациям осуществляющим деятельность в интересах общества в качестве основы для формирования требований к экологическим предпринимателям в Российской Федерации.

Ключевые слова: предпринимательство, экологическое предпринимательство, дефиниция, субъекты, экологический кризис, экологическое предпринимательство в США. 
3 агрязнение окружающей среды и нарушение целостности функционирования экосистемы является давней проблемой, необходимость решения которой с каждым днем становиться все актуальнее как во всем мире, так и в Российской Федерации, в частности. Как видно из сложившейся ситуации в сфере охраны окружающей среды, на данный момент предпринимаемых государством мер недостаточно. На наш взгляд, в сфере защиты и восстановления окружающей среды, а также воспитания экологически ответственного сознания может оказать весомый вклад развитие такого вида предпринимательской деятельности как экологическое, а именно экологическое предпринимательство. Необходимость защиты окружающей среды упоминается в множестве программных документов, в том числе стратегий развития, в которых также упоминается как экологическое предпринимательство, так и отдельные его виды, такие как экологический аудит, экологическое страхование, экологический туризм и другие, однако для полного понимания сущности, а также оптимального внедрения экологического предпринимательства в систему российского права, считаем необходимым изучить регулирование экологического предпринимательства в Соединенных Штатах Америки, так как в американской доктрине уделяется весомое внимание экологическим предпринимателям. Опыт Соединенных Штатов Америки может оказаться полезным и применимым в Российской Федерации.

Следует заранее отметить, что исследование данного вопроса затрудняет такое обстоятельство как посвящение в англоязычной литературе большого внимания исследованию личных характеристик предпринимателей, их внутренние мотивы и влияние их деятельности на экономику и общество при выборе в пользу экологического предпринимательства, в то время как вопросы правового регулирования указанными исследователями практически не затрагиваются, а также, то обстоятельство, что в разных штатах США существуют разные экологические стандарты и правовая система.

В американской науке на данный момент можно обнаружить активное продвижение идей устойчивого бизнеса (устойчивого предпринимательства) под которым обычно понимают «предприятие, которое оказывает минимальное негативное влияние на глобальную или местную среду, сообщество, общество или экономику бизнес, который стремится достичь тройного результата» [1], в американской научной литературе указанную деятельность также называют «зеленым» предпринимательство. Устойчивые предприятия известны своей прогрессивной политикой в сфере сохранения и защиты окружающей среды, а также прав человека. Очевидно, что слово «устойчивое» (англ. sustainable), применяется в соответствии с концепцией устойчивого развития (англ. sustainable development), следовательно, устойчивое предпринимательство основывается на принципах устойчивого развития, которые должны учитываться при каждом бизнес-решении, а также имеет большой уклон в сторону охраны окружающей среды.

Согласно бизнес словарю, экологический предприниматель (англ. еcopreneur) - предприниматель, который создает и продает экологически чистые продукты и услуги, включая экологически чистые продукты питания, переработку или экологичное строительство [2], в науке можно встретить более развернутые дефиниции, так как единого подхода относительно понятия экологического предпринимателя пока не сформировано, однако, ученые сходятся на двух базовых принципах, которыми являются улучшение состояния окружающей среды и извлечение прибыли, что касается соотношения «устойчивого» и «экологического» предпринимательства, то их надо соотносить как общее и частное. Ученые отмечают, что экологическое предприниматели в США имеют положительную репутацию, которая является конкурентным рыночным преимуществом. К экологическим предпринимателям в США относят компании применяющие экологически безвредные, устойчивые решения в своей деятельности, в частности в сфере управлениями отходами, выбросов углерода и применения возобновляемых источников энергии [3, Р. 233].

В качестве документа, регулирующего экологическое предпринимательство в США, можно отметить «Зеленые руководства» (англ. Green Guides), которые применяются в сфере маркетинга, относительно экологических характеристик продукции, и предостерегает от безоговорочных заявлений об экологической чистоте продукта, а также порядок применения печатей и сертификатов. Указанные «Зеленые руководства» принимает Федеральная торговая комиссия (англ. Federal Trade Commission) и следует отметить, что они не являются законом, а являются лишь руководством, относительно типов экологических требований, заявления относительного которых в случае введения в заблуждение потребителей, будет является основанием для применения мер воздействия со стороны Федеральной торговой комиссии согласно разделу 5 Закона «О Федеральной торговой комиссии» [4]. Особенностью опыта США является большое влияние экологических стандартов и руководств принимаемых частными субъектами (организациями, ассоциациями и другими НПО), которые функционируют вместе с государственными регуляторами.

Отметим, что в США налогом на прибыль облагаются деятельность коммерческих и некоммерческих организаций от неосновной деятельности. Источником финансирования экологических предпринимателей зачастую выступают частные фонды [5, с. 197]. Так как в США ан- 
глосаксонская система права, источником правового регулирования экологического предпринимательства выступают правовые прецеденты, а деятельность экологических предпринимателей регулируется различными публично-социальными институтами, в перечень которых помимо Агентства по охране окружающей среды, входят суды (как штатов, так и федеральные), законодательные органы штатов, которые принимают и толкуют нормы предпринимательского и корпоративного права.

В США традиционного экологическое предпринимательство исследуется в рамках экологического права или так называемого права окружающей среды. В доктрине США, существует подход расширительного толкования норм законов разных отраслей права в экологическом контексте, в частности и норм корпоративного права, которое в США регулирует отношения между акционерами, менеджерами фирмы и иным лицами, а следовательно может создавать стимулы, сдержки и запреты в целях экологически щадящего поведения. Гармоничный подход к указанным рычагам воздействия позволяет решить проблемы, с которыми не справляются традиционные законы в сфере охраны окружающей среды.

По мнению американских ученых в целях устранения кумулятивного вреда природоохранное право должно включать доктрины корпоративного и предпринимательского права, которые могут вызывать постепенные изменения в поведении фирм [6]. Однако, следует понимать, что в таком случае, расширительное экологическое толкование норм позитивного предпринимательского и корпоративного права не переведет указанные нормы в экологическое законодательство.

Согласно пояснениям Комиссии по ценным бумагам и биржам США, фирмы обязаны раскрывать потенциальное влияние изменения климата и нормативных актов в указанной сфере, что привело к положительному результату, так данные эмпирических исследований позволяют сделать вывод о положительной корреляции взаимосвязи финансовых показателей и экологических, социальных управленческих показателей [7, Р. 166].

Примером регулирования экологического предпринимательства нормами других отраслей права является дело, по которому были оштрафованы такие производители как Procter \& Gamble и Unilever за попытку избежать передачи на потребителей, экономии затрат от экологически выгодного продукта, в данном случае речь идет о регулировании экологического предпринимательства нормами антимонопольного законодательства [8].

В США существуют так называемые «корпорации осуществляющие деятельность в интересах общества» являющееся юридическими лицами. Первопроходцем в сфере внедрения корпорации осуществляющей деятельность в интересах общества является штат Мэриленд, учредивший устав указанной корпорации, к 2018 году подобные законы можно было найти уже в 34 штатах. Объединяющим моментом указанных законов является требование прозрачности и подотчетности, а также наличие в отношении целей корпорации общих черт [7, Р. 185].

Законы штатов регулирующие корпорации осуществляющие деятельность в интересах общества, предусматривают как учреждение указанной корпорации, так и преобразование существующей корпорации в корпорацию осуществляющуюдеятельность в интересах общества, по общему правилу, обычно предусмотрены требования специальной маркировки корпоративной документации, в отдельных случаях наименования с целью уведомления о том, что корпорация является корпорацией осуществляющей деятельность в интересах общества [7, Р. 187].

Главной особенностью корпорации, осуществляющей деятельность в интересах общества, является закрепление в уставных документах преследование такой общественной цели как положительное воздействие на окружающую среду и общество, однако отметим, что устав корпорации позволяет преследовать и иные социальные цели. Устав гарантирует защиту директоров от негативных явлений, создаваемых акционерами в форме реакции на экологически щадящую политику директоров и менеджмента идущую в разрез с основными экономическими целями - извлечение прибыли, так как в соответствии с корпоративным законодательством, директора фирм несут фидуциарные обязанности, перед корпорацией и ее акционерами [9], которые заключаются в осуществлении руководителем управленческих полномочий прежде всего в интересах бенефициара, исключая при этом частный интерес. Однако суды применяют правило о деловом суждении в отношении обычных решений, принимаемых менеджерами и директорами, в случае их действий в рамках разумного. Таким образом, продвижение такой долгосрочной ценности как защита окружающей среды в ущерб краткосрочной прибыли для акционеров будет логично рассматривать как надежную гавань, однако, если данная деятельность не будет переходить рамки разумного.

Корпорации осуществляющие деятельность в интересах общества обеспечивают публикацию ежегодного отчета для мониторинга соблюдения действий совершенных в интересах общества, в то время как оценкой эффективности занимаются независимые сертифицирующие организации [10].

В тоже время в доктрине США существуют и противники указанной корпоративной формы, видя в ней угрозу традиционному представлению об управленческом 
усмотрении, а также неразвитость контроля в сфере выполнения корпорацией декларируемых в её уставе целей.

Отметим что высокий вклад в экологическую ориентированность компаний в США внесли общественные организации и движения, в частности организованное экологами движение «Без ископаемых» а также такое движение как "Держи его в земле», действия которых привели к тому что крупные государственные инвестиционные фонды, кампусы начали отказываться от инвестиций в уголь, однако часть экономистов сомневаются в эффективности и указывают на символичность отказа от указанных инвестиций.

Ученые отмечают, что частные субъекты могут участвовать в управлении окружающей средой, причем не только в качестве следования нормативным требования публичного природоохранного законодательства, но и в качестве активных участников в установлении и обеспечении соблюдения экологических стандартов.

Так, в 2018 году Лоуренс Финк, генеральный директор инвестиционной компании BlackRock, крупнейший институциональный инвестор в мире, написал письмо генеральным директорам публичных компаний, в которые фирма инвестирует, предупреждая, что «со временем чтобы процветать, каждая Компания должна не только обеспечить финансовые результаты, но и показать, какой позитивный вклад в развитие общества вносит она» [11].

Относительно стандартов устанавливаемых частными компаниями Верховный суд США тщательно исследовав частные ассоциации по стандартизации [12], отметил, что, если ассоциации «обнародуют ... стандарты, основанные на достоинствах объективных экспертных суждений и с помощью процедур, которые не допускают предвзятости процесса стандартизации со стороны членов, имея экономические интересы в подавлении конкуренции за продукцию ..., эти частные стандарты могут иметь значительные конкурентные преимущества.» [13], однако важно отметить, что для эффективного функционирования частных отраслевых стандартов необходимы некие явные санкции в отношении несоответствующих стандартам участников отрасли.

Также, примечательно, что характеристики, которые отличали фирмы с высокой добровольной привержен- ностью устойчивости, включали более длительный период времени для принятия решений и подход, направленный на максимизацию «межвременной прибыли».

Однако сложно оспорить идею, что в той степени, в которой существует конфликт между экономическими и экологическими ценностями, необходимо отдавать приоритет окружающей среде, учитывая при этом необходимость в определенной степени пропорциональности, что можно охарактеризовать как принцип приоритета окружающей среды.

Таким образом, подводя итог, можно сделать вывод, что в Соединенных Штатах Америки, существует положительный опыт регулирования экологического предпринимательства, не взирая на отсутствие легального понятия под экологическим предпринимательством обычно понимают предпринимателей, деятельность которых направлена на улучшение состояния окружающей среды и извлечение прибыли. Само экологическое предпринимательство рассматривается в рамках права окружающей среды (экологического права), также популярны идеи расширительного экологического толкования норм иных отраслей права, так называемая экологизация права. Безусловным позитивным моментом экологического предпринимательства в США является высокий уровень саморегулирования в указанной сфере, формирование более высоких экологических стандартов и требований самими субъектами предпринимательской деятельности и иными частными субъектами. Важным моментом является существование в большинстве штатов США такой корпоративной формы как корпорация осуществляющая деятельность в интересах общества, которая позволяет заниматься экологической предпринимательской деятельностью, без угрозы для директоров и менеджмента привлечения к ответственности со стороны акционеров в случае деятельности согласно уставу корпорации осуществляющей деятельность в интересах общества. Приведенное позволяет прийти к выводу о возможности применения опыта Соединенных Штатов Америки в сфере регулирования экологического предпринимательства в Российской Федерации, в частности регулирования в России экологических маркировок на основе «Зеленых руководств», а требования к корпорациям осуществляющим деятельность в интересах общества могли бы послужить основой для формирования требований к экологическим предпринимателям в Российской Федерации.

\section{ЛИТЕРАТУРА}

1. Устойчивый бизнес [Электронный ресурс] // Multilingual dictionary.—Режим доступа: https://www.definitions.net/definition/SUSTAINABLE+BUSINESS

2. Ecopreneur [Электронный ресурс] // BusinessDictionary.—Режим доступа: http://www.businessdictionary.com/definition/ecopreneur.html 
3. Штефан Шальтеггер, Маркус Вагнер Устойчивое предпринимательство и инновации в области устойчивого развития: категории и взаимодействия // Business Strategy and the Environment Bus. Strat. Env.— 2011.— № 20. C. 222-237

4. ФТК приняла новые «Зеленные руководства» // Федеральная торговая комиссия: официальный сайт.—Режим доступа: https://www.ftc.gov/news-events/ press-releases/2012/10/ftc-issues-revised-green-guides

5. Гришина Я. С. Концептуальная модель правового обеспечения российского социального предпринимательства: дис. .... д-ра юрид. наук: 12.00 .03 / Гришина Яна Сергеевна.—M., 2016. - 503 c.

6. Katrina Fischer Kuh, Capturing Individual Harms // HARv. ENVTL. L. REV. — 2011.— № 35. C. 155-204.

7. Сара Э. Лайт Корпоративное право как экологическое право // Stanford Law Review. - 2019. - Toм 71. C. 137-213.

8. Решение Комиссии от 13 апреля 2011 года, дело СОМР / 39579 — потребительские моющие средства. С(2011) 2528 итоговое, 5, 23 [Электронный ресурс] // Режим доступа: https://pdfslide.net/documents/european-commission-brussels-1342011-c2011-2528-final-.html

9. eBay Domestic Holdings против Newmark, 16 A.3d 1, 26

10. Модельный закон о корпорациях осуществляющих деятельность в интересах общества § $401-402$.

11. Ларри Финк, Ежегодное письмо «Чувство цели» генеральным директорам, BLACKROCK. [Электронный ресурс] // Режим доступа: https://perma.cc/YUE5BNZC

12. Allied Tube \& Conduit Corp. против Indian Head, Inc., 486 U.S. 492, 500-01 (1988).

13. ФТК и Министерство юстиции США, Антимонопольное руководство по сотрудничеству между конкурентами 5-6 (2000). [Электронный ресурс] // Режим доступа: https://perma.cc/B9KS-LUVJ

( Элларян Артур Сашикович ( tlon9@rambler.ru ).

Журнал «Современная наука: актуальные проблемы теории и практики»

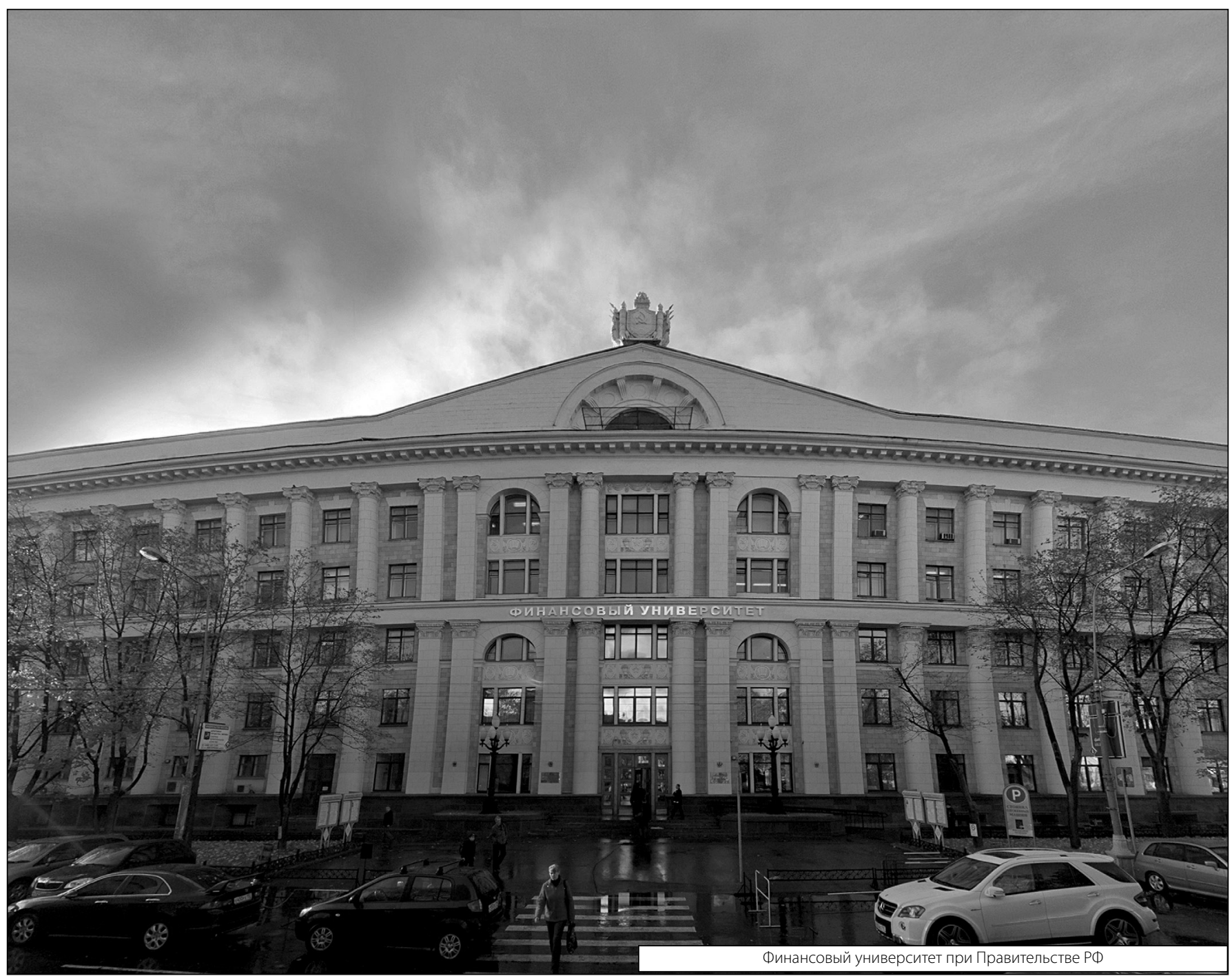

